\title{
ANÁLISE DAS CARACTERÍSTICAS DETERMINANTES DAS EMPRESAS QUE USUFRUEM DE SUBVENÇÕES E ASSISTÊNCIAS GOVERNAMENTAIS
}

\section{ANALYSIS OF DETERMINING FEATURES OF COMPANIES THAT BENEFIT FROM GOVERNMENTAL GRANTS SUBSIDIES}

\section{ANÁLISIS DE LAS CARACTERÍSTICAS DETERMINANTES DE LAS EMPRESAS BENEFICIARIAS DE SUBVENCIONES Y AYUDAS DEL GOBIERNO}

Recebido em: 29/07/2016

Avaliado em: 07/10/2018

Reformulado em:05/03/2018

Aceito para publicação em: 18/07/201 ${ }^{1} 9$

Publicado em: 30/11/2019

Editor Responsável: Tarcísio Pedro da Silva
Diana Maria Preciado Saac

Amaury José Rezende 2

\section{RESUMO}

O presente estudo teve como objetivo identificar as características das empresas que usufruem de subvenções e assistências governamentais. A amostra pesquisada compreendeu 791 notas explicativas de 113 empresas listadas no índice IBRX-100 da Bm\&fBovespa, nos períodos de 2008 a 2014. As análises descritivas indicam que 48 empresas (43\% da amostra) participaram de algum programa de Subvenção Governamental, totalizaram aproximadamente R \$ 30 bilhões, dentre os setores e regiões que mais apresentam empresas detentoras de subvenções estão: i) Setores: energia elétrica, consumo cíclico, comércio, construção e engenharia, e metalúrgica; e ii) Regiões: São Paulo, Rio de Janeiro e Minas Gerais. Os resultados obtidos com nas análises de regressão logísticas indicam que há uma probabilidade maior das empresas que possuem subvenções nas seguintes características: empresas mais lucrativas; tamanho da empresa, captação de recursos junto ao BNDES e ser auditada por um empresa Big4. Cabe esclarecer que a adoção das normas internacionais aumentou o nível de divulgação das informações referentes aos programas de subvenções e assistências governamentais, bem como os respectivos valores transacionados.

Palavras-chave: Subvenções; Assistências Governamentais; Incentivos fiscais; CPC 07 (R1).

\section{ABSTRACT}

This study aimed to identify the characteristics of companies that receive government grants. We reviewed 791 notes to financial statements from 113 companies listed in the BM\&FBovespa index IBRX-100, from 2008 to 2014. Descriptive analyzes indicate that 48 companies (43\% of the sample) participated in some of the stablished Government Grant programs, totaling approximately R \$ 30 billion, and shows that the most benefited sectors and regions are: i) Sectors: electricity, cyclical consumption, trade, construction and engineering, and metallurgy; and ii) Regions: São Paulo, Rio de Janeiro and Minas Gerais. The results from logistic regression applied indicate that there is a

\footnotetext{
1 Mestre em Controladoria e Contabilidade pela Universidade de São Paulo - Ribeirão Preto; E-mail: dianapreciado@usp.br

${ }^{2}$ Doutor em Controladoria e Contabilidade pela Universidade de São Paulo; Professor do Programa de Pós-Graduação em Controladoria e Contabilidade da Universidade de São Paulo - Ribeirão Preto; E-mail: amauryj@usp.br
} 
greater opportunity for subsidized companies with the following characteristics: more profitable companies; company size, funds raised from BNDES and being audited by a Big4 company. It should be clarified that the adoption of international standards has increased the level of disclosure of information regarding government grants and assistance programs, as well as the respective amounts traded.

Keywords: Governmental Grants; Tax incentives; IAS 20.

\section{RESUMEN}

Este estudio tuvo como objetivo identificar las características de las empresas que reciben subvenciones gubernamentales. Revisamos 791 notas explicativas de 113 empresas que figuran en el índice BM\&FBovespa IBRX-100, del 2008 al 2014, los análisis descriptivos indican que 48 empresas (43\% de la muestra) participaron de algún programa de incentivo, totalizando aproximadamente R\$ 30 billones, entre los sectores y regiones con más compañías beneficiadas: i) Sectores: electricidad, consumo cíclico, comercio, construcción e ingeniería, y metalurgia; y ii) Regiones: São Paulo, Río de Janeiro y Minas Gerais. Los resultados de los análisis de regresión logística indican que existe mayor probabilidad en las empresas subvencionadas cuando presentan las siguientes características: son empresas más rentables; el tamaño de la empresa, si capta fondos del BNDES y, el ser auditados por una empresa Big4. Se observó también que la adopción de las normas internacionales de contabilidad aumento el nivel de divulgación de información sobre los programas de asistencia y subsidios del gobierno, así como los respectivos montos recibidos.

Palabras-clave: Subvenciones; Ayudas del Gobiern;. Incentivos Fiscales. NIC 20.

\section{INTRODUÇÃO}

O processo de industrialização sempre foi bandeira defendida como o motor do crescimento econômico nos países latino-americanos, pois todo a dinamicidade e capacidade de inovação eram obtidas nas operações das indústrias. Lamonica e Feijó (2007) destacam que as inter-relações da indústria com outros setores econômicos produziam o aumentado de produtividade. No entanto, as indústrias em geral sempre alegaram que para alcançar certo nível de desenvolvimento econômico, os governos locais (destes países) devem oferecer condições vantajosas para enfrentar as constantes e difíceis mudanças socioeconômicas.

A institucionalização de políticas físcais (desoneração) é uma das formas que tem sido oferecida pelos governos para o enfrentamento destas dificuldades, por meio da criação de políticas de incentivos e financiamento públicos, os quais promovendo ganho fiscal as empresas em troca da geração de empregos e desenvolvimento local. Essa ação é uma estratégia desastrosa que se tem utilizado como contraponto às ineficiências do poder público que não consegue sanar as s inúmeras necessidades de infraestrutura e serviços públicos de qualidade, que são requeridas pela sociedade, tais como educação, saúde, moradia, água, segurança, entre outras (Cardoso Júnior, 2010; De Luca \& Lima, 2007).

Para Li (2002) existe institucionalizado uma crença de que o mercado de capitais não fornece as formas de financiamento adequadas para as empresas ou para formação de novos negócios, sendo a que a criação de programas de assistências ou incentivos seria uma justificativa válida para o governo combater a falta de estímulos na economia. Nesse contexto, tem-se surgido questionamentos quanto a efetividade destes incentivos oferecidos, considerando duas perspectivas: a) uma do ponto de vista de quem os concede, que neste contexto é o Governo, b) e a outra do ponto de vista de quem os recebe, as empresas. Klemm e Van Parys (2012) questionam se estes incentivos são utilizados atualmente como ferramentas de concorrência fiscal no país, ademais eles questionam também se são eficazes para atrair investimentos. 
Peters e Fisher (2004) enumeram duas possíveis justificativas possíveis utilizadas para a concessão de incentivos: i) o fomento do investimento econômico e a criação de empregos, produzindo maior demanda local de bens e serviços; e ii) dado este crescimento econômico, este aumento nos recursos públicos permita uma melhor distribuição dos recursos para melhoria e otimização dos serviços do Estado, a partir da obrigatoriedade dos tributos a serem arrecadados. Além disso, no cenário atual muitas empresas são contempladas com o "combo fiscal" captam recurso em bancos públicos (taxas subsidiadas) para implementação de seus projetos operacionais, através dos mecanismos de dívida; obtenção de subvenções dos tributos incidentes sobre as suas operações (municipais, estaduais e federal); e obtenção de doações de infraestrutura doadas pelas localidades hospedeiras (Rezende, 2015).

No Brasil, estes benefícios fiscais visam incrementar o fluxo de operações econômicas das empresas, atrair investimentos em determinadas regiões pouco desenvolvidas e outras finalidades no tocante ao caráter econômico e social (Taveira, 2009).

Rezende (2015) identificou que é bem variado o portfólio de subvenções governamentais ( 88 tipos), que vão dos que estão condicionados ao repasse a programas previamente definidos pelo governo, que representam ações de intermediação dentre a empresa e a sociedade. Neste contexto, a empresa torna-se um agente econômico socialmente responsável com a promoção de políticas públicas. Por exemplo, algumas diretrizes destes tipo de benefícios se encontram especificados no site da Receita Federal, tais como o Programa de Alimentação do Trabalhador (PAT), as doações feitas aos Fundos da Criança e do Adolescente, os referentes à Lei do Idoso, de atividades Culturais, Artísticas e Atividades Audiovisuais, assim com doações para áreas de saúde, como por exemplo, o Programa Nacional de Apoio à Atenção da Saúde da Pessoa com Deficiência (PRONAS) e Incentivos Fiscais - Programa Nacional de Apoio à Atenção Oncológica (PRONON).

Ademais, as empresas também podem se beneficiarem de outros incentivos, tais como depreciação acelerada incentivada e os incentivos à inovação tecnológica, assim como outros vinculados à legislação do imposto de renda. Cabe esclarecer que muitas empresas tendem a não aproveitar, na sua grande maioria, por desconhecimento provavelmente.

No Brasil, atualmente, as subvenções e assistências governamentais são reguladas pelo Comitê de Pronunciamento Contábil CPC 07 R1(2010). Este pronunciamento revoga o aprovado previamente em 03/10/2008 e foi elaborado a partir do IAS 20 - Accounting for Government Grants and Disclosure of Government Assistance emitidos pelo International Accounting Standards Board (IASB).

A norma contábil, independentemente da forma ou natureza em que estas subvenções e assistências governamentais sejam recebidas, exige as beneficiadas que realize o reconhecimento, a mensuração e a divulgação em suas demonstrações contábeis, monetariamente. Isso permite o usuário da informação distinguir os efeitos das subvenções empresa aos ganhos com as operações normais da entidade.

O presente estudo tem como objetivo identificar as características das empresas que receberam subvenções e assistências governamentais, de forma específica busca:

I. Identificar os setores econômicos que mais recebem subvenção governamental; e

II. Avaliar há uma probabilidade de discriminar os grupos de empresas que recebem e não recebem por suas características econômicas e operacionais, via regressão logística.

Este trabalho encontra-se estruturado em cinco sessões: a primeira inclui esta introdução; a segunda traz uma revisão da literatura e os aspectos conceituais sobre as políticas de subvenções governamentais que envolve o tema; a terceira trata dos aspectos metodológicos; a quarta demonstra os resultados apurados nas análises; e, por fim, na quinta sessão, são apresentadas as considerações finais da pesquisa. 


\section{REFERENCIAL TEÓRICO}

\subsection{Políticas e Programas de subvenções governamentais}

s subvenções, no caso dos incentivos fiscais, são consideradas instrumentos utilizados pelos Estados para alcançarem seus resultados. Estes benefícios são considerados como bens públicos, que foram concedidos em troca de compromissos das empresas (Campanelli, 2010).

O Pronunciamento Técnico CPC 07 define que

[...] a assistência governamental compreende uma ação de um governo, destinada a fornecer um benefício econômico específico a uma entidade ou a um grupo de entidades que atendam os critérios estabelecidos; a subvenção governamental representa uma assistência governamental, geralmente na forma de contribuição de natureza pecuniária, mas não só restrita a ela. Este aporte pode ser oferecido como um ativo ou outras formas que não envolvam a entrega do dinheiro, mas que sejam quantificáveis (CPC, 2010).

Estas subvenções são concedidas "em troca do cumprimento passado ou futuro de certas condições relacionadas às atividades operacionais da entidade" (CPC, 2010).

Dado que as subvenções e assistências governamentais são formas de intervenção do Estado na economia, Campanelli (2010) destaca, ainda, que é de competência do governo estabelecer os delineamentos e os mecanismos de fiscalização e monitoria para o cumprimento, tal como indica a Constituição da República Federativa do Brasil, no seu artigo 174: "Como agente normativo e regulador da atividade econômica, o Estado exercerá, na forma da lei, as funções de fiscalização, incentivo e planejamento, sendo este determinante para o setor público e indicativo para o setor privado" (Brasil, 1988).

As subvenções dadas às empresas deveriam ser revertidas, em prol da sociedade, pela geração de empregos diretos e indiretos. Nessa linha, Fonteles et al. (2014) afirmam que os benefícios concedidos às empresas, por uma perspectiva social, são bens e direitos públicos, que pertencem à sociedade. Assim, quando recebe uma subvenção, a entidade pode passar uma imagem de expropriação dos bens públicos em benefício particular.

As subvenções podem assumir diversas e natureza ou ter condições especificas, por exemplo: i) Subvenções relacionadas a ativos, por exemplo: um terreno, no qual o uso do bem pode vir com restrições, tais como condições específicas para construção; e ii) Subvenções relacionadas a resultado ou assistência financeira, tais como os incentivos fiscais de custeio e os empréstimos subsidiados; iii) Incentivos Fiscais aplicáveis ao imposto sobre a renda e contribuições, esses se apresentam na forma de isenção ou redução dos referidos tributos de acordo com a legislação específica. Este tipo de subvenção é muito oferecido internacionalmente, principalmente em países em desenvolvimento para atrair investimento local e estrangeiro. Assim, o governo tenta oferecer um tratamento fiscal mais favorável para incentivar certas atividades econômicas (Klemm \& Van Parys, 2012).

Busom et. al (2015) alertam que a concessão desses benefícios não é livre de erro, pois os benefícios concedidos possuem uma assimetria informacional no momento da seleção de cada projeto. Eles acrescentam que uma análise dos benefícios e dos efeitos potenciais deveria ajudar na correção de tais erros durante o processo de seleção.

Tem em vista, que as beneficiadas prometem a entregam de diversos benefícios a região e a econômica local, que vão da geração de empresas, transferência de tecnologia pela execução de seus projetos. No entanto, na prática é bem diferente do que a sociedade recebe de accontability das empresas beneficiadas, pelos menos no ambiente dos programas fiscais estaduais e locais (Rezende, 2015).

Acredita-se que os incentivos fiscais estimulam o esforço inovador das empresas que já investiram na área de pesquisa e desenvolvimento anteriormente. Mesmo assim, não se pode indicar que a inovação incentivada compense socialmente o custo da perda de recursos públicos (Busom et. al., 2015). 
Em linhas gerais, no Brasil a prática mais usual é a isenção tributária que compreende a desobrigação legal do pagamento total ou parcial dos tributos. Formigoni (2008, p. 14) destaca que os incentivos fiscais correspondem a um benefício na medida em que os recursos não aplicados para o pagamento de tributos sejam aproveitados e investidos em outras áreas da empresa para melhorar seu desempenho econômico, portanto, o incentivo fiscal pode ser visto como uma fonte de financiamento para a empresa na medida em que deixa de recolher os impostos, ela pode aplicar esses recursos em outros ativos ou processos ligados à sua atividade principal com o objetivo de obter um melhor desempenho econômico e financeiro.

\subsection{Aspectos Técnicos do Tratamento contábil}

A informação contábil tem como finalidade emitir sinais sobre os impactos econômicos e financeiros das empresas beneficiadas diminuindo assim assimetria informacional entre os usuários da informação envolvidos (Acionistas, Poder Público e a sociedade impactada), no que tange à demonstração do recebimento de subvenções governamentais, bem como resultados proporcionados pelo programa instituído.

Neste caso, a contabilidade, como ferramenta de controle, tem um papel fundamental no registro e mensuração das assistências e subvenções governamentais, pois elas possuem características diferenciadas das cotidianas, assim as empresas beneficiadas devem demostrar transparência ao evidenciar o impacto das subvenções sobre o desempenho das entidades economicamente afetadas por esses programas.

O Pronunciamento Contábil CPC 07 (R1) (2010) determina que "uma subvenção governamental deve ser reconhecida como receita confrontada com as despesas que pretende compensar". A subvenção governamental não pode ser creditada diretamente no patrimônio líquido, tendo em vista que não corresponde a aportes financeiros dos acionistas. Portanto, qualquer que seja a forma de recebimento de uma subvenção, a norma contábil indica que deve ser reconhecida como receita somente depois de cumprida duas regras: i) sejam cumpridas as condições estabelecidas e relacionadas ao programa de subvenção e ii) obter-se o seu recebimento efetivo.

As subvenções devem ser divulgadas em notas explicativas, conforme o item 39 do CPC 07 (R1), discriminado:

a. A política contábil adotada para as subvenções governamentais, incluindo os métodos de apresentação adotados nas demonstrações contábeis;

b. A natureza e a extensão das subvenções governamentais ou assistências governamentais reconhecidas nas demonstrações contábeis e uma indicação de outras formas de assistência governamental de que a entidade tenha diretamente se beneficiado; e

c. As condições a serem regularmente satisfeitas e outras contingências ligadas à assistência governamental que tenha sido reconhecida .

Fortin, Barros e Cutler (2010) ressaltam que o investidor, o governo, os agentes externos e demais usuários recorrerão às informações contábeis, pois esperam elas sejam fidedignas, livres de erros e com qualidade. Acrescentam que também se espera que as empresas beneficiadas promovam a transparência dos impactos das desonerações fiscais sobre o seu desenvolvimento econômico e da comunidade/região em que atual, bem realizem periodicamente a prestação de contas ao setor público.

\subsection{O oferecimento de subvenções governamentais e as suas contradições}

Filho (2010) esclarece que aceitar argumentos opostos a concessão de subvenções seria num mundo de concorrência perfeita e sem assimetrias de informação, onde os agentes econômicos contariam com acesso a mesma informação de forma homogênea.

Crispim (2011) destacam que as subvenções eram vistas como recursos públicos que o Governo disponibilizava como favores a amigos. A justificativa que tem se utilizado é que esses recursos cedidos passaram a ser utilizados como ferramenta de desenvolvimento econômico. $\mathrm{Na}$ 
prática, Bartik (2005) afirma que colocar em prática o controle sobre o oferecimento de subvenções governamentais e incentivos pode ajudar o governo na identificação antecipada dos requisitos mínimos que um projeto deveria cumprir. Portanto, a proposta é interessante, mas não é possível aferir com precisam se os entes regulatórios têm realizado uma avaliação dos programas a concessão tem sido adequada, e se eles têm promovidos efetivamente ganhos para a sociedade, como por exemplo, na criação de empregos.

Rezende et at. (2019) analisaram se as subvenções governamentais (benefícios fiscais) impactam a criação de valor para as empresas instaladas na cidade de Três Lagoas-MS, de 2000 a 2014. Eles estimaram que para cada emprego prometido há um custo fiscal para de sociedade R \$ 9.886,57, em média (mês), decorrente da desoneração fiscal dada às empresas.

Klemm (2010) estudou as circunstâncias em que os países deveriam optar pelo oferecimento de incentivos, seja para atrair certo tipo de investimento em nível regional ou internacional ou para corrigir falhas do mercado. $\mathrm{O}$ autor indica que o oferecimento de incentivos deveria ser considerado por níveis:

1) Relativamente Forte: quando a atividade econômica é considerada internacionalmente competitiva, ou seja, trata-se de uma indústria competitiva; e, quando existem externalidades positivas, o país pode oferecer subsídios baseados na atividade operacional da empresa e incentivos para fomentar áreas de pesquisa e desenvolvimento;

2) Ambíguo: quando se consideram as rendas a nível regional, considerando a localização de regiões pouco atraentes ou quando se considera que a diminuição da taxa impositiva pode provocar reações negativas em outras regiões; e

3) Fraco: quando podem existir, numa região, rendas exógenas por esta se tratar de uma localização protegida ou específica, ou caso exista exploração de recursos naturais.

Filho (2010) acrescenta que o oferecimento deste tipo de benefício deve ser feito de forma responsável, com o intuito de cumprir a função de atrair investimento, mas obedecendo aos critérios relacionados às necessidades pré-existentes na região ou local e que, mediante seu oferecimento, seja permitido impulsionar o desenvolvimento econômico dessa região.

A partir destas características é possível determinar que a análise das necessidades identificadas numa região pode levar os governos oferecerem incentivos mais adequados. Nessa linha Klemm (2010) argumenta que uma resposta racional poderia encaminhar ações que beneficiariam as pressões da concorrência fiscal, além de permitindo o surgimento de um sistema fiscal competitivo.

Klemm e Van Parys (2012) trataram da relevância da alíquota de Imposto de renda (IR) e como a isenção do pagamento do imposto de renda impacta a atração de Investimento Direto Estrangeiro (IDE) em Países Latino-Americanos e no Caribe. Os autores entendem que estes países estão, de fato, competindo para atrair novos investimentos. Eles concluem que a relação entre investimentos e incentivos fiscais nos países em desenvolvimento dependem do significado e da prioridade dos investimentos que cada país necessita e o tipo de incentivo que cada região pode oferecer.

Já no contexto das opções que as empresas têm disponíveis para custear seus projetos, o panorama que oferece a Teoria de Pecking Order, adaptada por Myers (1984), abarca a discussão central de que existe uma ordem no momento de escolher fontes para se financiar. $\mathrm{O}$ autor sugere que a assimetria informacional cria uma preferência no momento de decidir qual fonte de financiamento será escolhida. Neste caso, como a empresa (representada pelos gestores) possuem mais informação sobre a sua situação econômica, optará por uma fonte interna de financiamento ao invés de captar fontes de terceiros. Uma vez limitadas as fontes internas, os gestores optariam por escolher o endividamento, sendo que a emissão de novas ações no mercado de capitais seria a última fonte de recurso.

Nessa linha, Rezende (2015) identificou que as empresas brasileiras têm optado por uma fonte alternativa de recurso, que vai além do rol de opções listadas pela Teoria de Pecking Order. As 
empresas têm se financiado com o tributo esse financiamento tem ocorrido basicamente de três formas: i) subvenções governamentais estaduais prioritariamente; ii) Protelamento do pagamento dos tributos devidos ao ciclo instituição do programas de refinanciamento de dívidas, tanto no nível federal quanto estadual tem ocorrido a cada 3 anos em média; e iii) a obtenção de financiamentos junto aos bancos públicos com juros subsidiado.

Zee, Stotsky e Ley (2002) questionam a efetividade de outorgar incentivos fiscais para as firmas no desenvolvimento dos seus projetos. Pois, a relação entre o estado e as empresas é possuem assimetria informacional. Bartik (2005) elucida essa questão sobre a perspectiva da Teoria de Agência, na qual se busca descrever a relação entre o principal, que tem o controle, e o agente, que exerce as funções em troca de uma remuneração, poderia se dizer que as subvenções representam uma remuneração oferecida ao agente (empresa subvencionada) por este exercer funções em nome do principal (o Governo). O principal então demandaria do agente que este cumprisse as condições e restrições específicas, para maximizar a sua utilidade, e retribuí-la através do esforço do agente na sociedade.

Sullivan (2002) argumenta que a relação contratual entre empresa e estado para os países menos desenvolvidos, eles tomam mais riscos e abarcam maior nível incertezas, pois não segurança de que as empresas incentivadas beneficiarão a região, por exemplo, aumentando empregos, salários ou a produtividade mediante a produção de bens e serviços.

Klemm e Van Parys (2012) tentaram explicar porque o oferecimento de incentivos fiscais reage no investimento. Os autores argumentam que as empresas irão acumular seu capital sempre que os benefícios excedam os custos. Assim, o investimento aumenta se as subvenções diminuem o custo do uso de capital. Por exemplo, na Irlanda, Girma, Görg e Strobl (2007) destacam que os projetos das empresas com maior oportunidade de receber subvenções e assistências governamentais se os que se dedicam a produzir e exportar bens, contudo essas empresas em geral já contam com alta capacidade tecnológica e de comercialização dos seus produtos internacionalmente. Ademais estas empresas beneficiadas devem demonstrar a viabilidade do projeto proposto além de participarem com uma adequada base de capital próprio.

Hall, Hutchinson e Michaelas (2004) analisaram se a estrutura do capital das firmas é determinada por características específicas. Eles concluem que as variáveis como rentabilidade, crescimento, estrutura dos ativos, tamanho da firma e a idade das pequenas e médias empresas (PME) europeias (Bélgica, Alemanha, Espanha, Irlanda, Itália, Holanda, Portugal e Reino Unido) apresentam diferenças dentre os países. As diferenças encontradas sinalizam que não há um efeito direto sobre a estrutura de capital das PMEs. Os autores conjecturam que as variações específicas das características da firma podem ser explicadas pelas diferenças no nível de requerimento de divulgação da informação contábil, da relação com os bancos, das taxas impostas dentre outras diferenças socioculturais. Por fim, adicionam que estas diferenças estariam relacionadas aos diferentes níveis de assimetria informacional e aos custos de sinalização entre os países.

Bernardo et. al (2010) analisaram como as subvenções estimulam os investimentos de empresas com foco em práticas de responsabilidade social. Eles identificaram uma reação positiva destas empresas na adesão de incentivos federais, tais como os aplicados à educação, cultura, e atividades desportivas, saúde, dentre outros. Os autores sugerem que as empresas podem livremente participar desses programas com o intuito de gerar benefícios à sociedade sem que se descuidem dos interesses dos seus investidores (acionistas).

\subsection{Desenvolvimento das hipóteses}

Com adoção das normas interacionadas de contabilidade, no âmbito nacional, houve modificações no padrão de exigência da evidenciação de subvenções recebidas pelas empresas. Além disso, nas últimas décadas houveram diversas discussões sobre "Guerra Fiscal" nos Estados, no âmbito jurídico, com o intuído de barrar a concessão de benefícios pelos estados. Destacam foi 
editado a Resolução SF n ${ }^{\circ} 13 / 2012^{3}$ que instituiu alíquota única de 4\% de ICMS para os produtos importados.

A guerra fiscal não é fenômeno exclusivo do Brasil, Chirinko e Wilson (2008) investigaram a efetividade e a extensão dos programas de benefícios em 48 Estados Norte-Americanos e constataram evidências sobre os efeitos mensuráveis da aplicação de incentivos para o custeio de investimento.

Loureiro, Gallon e De Luca (2011) investigaram os efeitos econômicos e o nível de divulgação contábil das subvenções governamentais, desenvolveram um estudo com base nos indicadores econômicos das 100 maiores empresas de capital aberto listadas na Bm\&fBovespa, nos períodos 2008 e 2009. Dentre os achados os autores destacaram que os setores de Energia, Bens de Consumo e Telecomunicações foram altamente beneficiados com subvenções, mas as empresas apresentaram um nível baixo de evidenciação contábil, afirmando que nesse período as empresas ainda precisavam se adaptar às mudanças e exigências normativas com o processo de convergência as normas internacionais IFRS, no Brasil. Diante dessas evidências a Priore, nessas pesquisas, conjectura-se que:

Hipótese (H1): a adoção das IFRS contribuiu para a divulgação das subvenções recebidas, além de ser uma característica importante para a classificação de uma empresa na categoria daquelas que usufruem de Subvenções e Assistências Governamentais.

Rodrigues Júnior (2003) utilizou a Demonstração de Valor Adicionado (DVA) e, por meio de uma survey, desenvolveu um estudo de caso com duas empresas no setor têxtil no Estado do Ceará. $\mathrm{O}$ autor mensurou se há uma relação de custo-benefício para o recebimento de incentivos fiscais para estas empresas e identificou que os custos de outorgar estes incentivos foram menores que os benefícios proporcionados para a região.

De Mendonça et al. (2013) estudaram o setor elétrico e identificaram que estatisticamente o recebimento de subvenções, por parte destas empresas, se mostrava positivo diante do seu desempenho econômico, mas ressaltavam que estas empresas já eram lucrativas. Assim, esses resultados podem indicar a seguinte hipótese $(\mathrm{H} 2)$, que:

Hipótese (H2): a participação da empresa em um setor econômico específico pode constituir uma característica determinante para a classificação das empresas que usufruem de Subvenções e Assistências Governamentais.

Baghana e Mohnen (2009) e Bérubé e Mohnen (2009) analisaram se o nível de inovação tecnológica é também tomado como indicador de desempenho econômico e a relação com o oferecimento de subsídios, créditos e incentivos oferecidos para projetos de pesquisa e desenvolvimento e de inovação tecnologia nas indústrias manufatureiras.

Bérubé e Mohnen (2009) investigaram via aplicação de questionários junto aos gestores de pequenas, médias e grandes indústrias canadenses, que receberam ou incentivos fiscais, créditos, ou ambos, a serem utilizados na área de pesquisa e desenvolvimento. Os autores chegaram à conclusão de que, no contexto canadense, para se executar uma política fiscal de apoio à Pesquisa e Desenvolvimento (P\&D) mais eficiente (na província de Quebec), seria aconselhável continuar usando créditos fiscais graduais em favor de pequenas empresas, visto que são estas as que têm maior dificuldade em obter financiamento externo para seus projetos.

Bérubé e Mohnen (2009) também destacam que no contexto canadense há diferentes tipos de auxílios que vão desde créditos a subvenções diretas para as áreas de pesquisa e desenvolvimento das empresas. Esses programas são oferecidos nas mais diferentes eu províncias, sendo que algumas regiões as empresas teriam maior oportunidades que outras. Por fim, eles acrescentam que as

\footnotetext{
${ }^{3}$ Com o objetivo de eliminar a denominada "Guerra Fiscal", onde Unidades da Federação concedem benefícios fiscais para empresas instaladas em seus territórios sem respaldo em convênio ICMS, condição essa exigida pela Constituição Federal de 1988 e pela Lei Complementar n 24/1975, o Senado Federal editou a Resolução SF nº $13 / 2012$ para fixar em $4 \%$ a alíquota interestadual do ICMS nas operações com bens e mercadorias importadas do exterior, a partir de $1^{\circ} .01 .2013$.
} 
empresas que recebem ambos os tipos de programas têm mais oportunidades de introduzir e comercializar suas inovações.

Peters e Fisher (2004) procuraram, no contexto norte-americano, respostas às questões relacionadas à concessão de subvenções e assistências governamentais, tais como: se os incentivos econômicos ajudam a promover à geração de emprego? Se os benefícios estão sendo direcionados as áreas economicamente necessitadas. Eles ressaltam que os incentivos é tema custoso para os governos, pois, as subvenções e assistências governamentais estão sendo concedidas sem uma quantificação da contribuição e o que oferecem em contrapartida à sociedade.

Bondonio e Greenbaum (2007) analisam o impacto dos diferentes programas e Políticas de Incentivos aplicados nas zonas empresariais e em diferentes tipos de atividades econômicas dos Estados Unidos. Dentre os tipos de incentivos foram encontrados os diretamente vinculados à criação de empregos, ao aumento no nível de vendas e nos gastos de capital. Os pesquisadores apontam que os negócios já existentes são os que se veem afetados de forma positiva por estas políticas de incentivo. Eles apontam o fato de que as empresas novas ainda não têm uma lucratividade suficiente nos primeiros anos.

Klemm (2010) analisou a utilização de incentivos fiscais como ferramenta de concorrência fiscal, que é mais comum em países em desenvolvimento. Ele considerou como certos fatores ou características relacionadas ao oferecimento de incentivos fiscais, no campo e em atividades empresariais internacionais as possíveis externalidades, a renda da região, e a região quando se mostrar pouco atrativa para os investidores. Ele conclui que a concorrência fiscal é provavelmente a grande força motriz para as reformas fiscais e discute que o oferecimento destes incentivos como uma possível resposta.

Klemm (2010) justifica que a concessão de um incentivo fiscal está relacionada ao fato de que o sistema fiscal representa um forte obstáculo para atração de investidores, seja para a obtenção de capital ou alguma outra forma de financiamento. De acordo aos autores, isto é importante porque os investidores, antes de se envolver em um grande investimento, precisariam entender os fatores tributários e legais, assim como os esquemas e mecanismos destes incentivos para poder basear as decisões de investimento sobre eles.

No contexto brasileiro, De Luca e Lima (2007) investigaram em suas análises os benefícios oferecidos no Estado do Ceará, via Fundo de Desenvolvimento Industrial (FDI). Concluem que o Fundo de desenvolvimento ter atraído empresas, ademais tem contribuído para a melhoria dos índices econômicos das empresas beneficiárias, assim como também tem se mostrado positivos na geração de mais oportunidades de emprego promovendo uma melhora na economia da região. Nessa linha, Cerqueira (2007) analisou os tipos de investimentos realizados nas indústrias de transformação baianas, entre 1994 e 2004. Nesta pesquisa considerou como os investimentos podem produzir reflexos sobre a economia baiana e sobre as condições de vida dos cidadãos. Constata-se que nesse período houve um aprofundamento das características estruturais da economia baiana como: a dependência tecnológica, os baixos encadeamentos produtivos, a ampliação dos centros de decisão externos ao estado, a pequena capacidade de incorporação de mão de obra e o aumento da concentração de renda. Todos os aspectos relatados evidenciam o subdesenvolvimento desse estado se intensificaram (Cerqueira, 2007).

Diante dos estudos anteriores apresentados sugere a seguinte hipótese:

Hipótese (H3): a região ou localização em que a empresa está instalada constitui-se uma característica para a classificação na categoria daquelas que usufruem de subvenções e assistências governamentais.

Bergamaschi (2009) fornece no seu estudo um referencial teórico histórico sobre as Leis de incentivo na perspectiva da pesquisa em desenvolvimento e inovação, com maior foco na utilização dos incentivos fiscais para inovação tecnológica concedidos pelo governo na Lei 11.196 de 2005. Ele destaca que mesmo diante dos riscos e incertezas quanto ao retorno que será obtido com a concessão de benefícios recomenda a continuidade deste tipo de pesquisa que avalie se os incentivos a inovação 
tecnológica por parte das empresas em diferentes setores econômicos tem transferido tecnologia e proporcionado uma contribuição inovadora ao processo produtivo, que é vital para o desenvolvimento econômico e social de um país.

Rezende (2015) analisou o impacto dos incentivos fiscais sobre os retornos, as políticas de investimento e decisões de financiamento das empresas, foram analisadas 653 empresas, no período de 2011 a 2013. Demonstrando assim que os incentivos fiscais têm relação positiva com a geração de valor nas empresas. Ele constatou que os benefícios são estatisticamente significativos com os drives de criação de valor. No Tocante, a destinação do valor criado identificou correlações estatisticamente significantes, sendo que há uma correlação negativa com o nível de endividamento, correlação positiva com o fluxo de caixa operacional e negativa com o fluxo de caixa de investimento, por fim apurou correlação positiva entre participar de programas e subvenções governamentais com a distribuição de resultados (dividendos e juros sobre capital próprio). A partir dos resultados deste autor formulou a seguinte hipótese:

Hipótese (H4): a obtenção de financiamento de empréstimos junto ao BNDES constitui característica para a classificação.

Em relação aos determinantes e escolha do tipo de dívida de longo prazo, Hall, Hutchinson e Michaelas (2004) identificaram que a idade da empresa é determinante significativo, sendo que, para os autores, quanto mais tempo no mercado, mais ela é capaz de acumular fundos e, quanto mais nova, por não contar com os recursos necessários, mais poderia contrair dívidas de curto a longo prazo. No caso de não optar por dívida, ela iria procurar outra forma de financiamento, e as subvenções governamentais poderiam ser uma alternativa. Assim, de acordo com o autor, quanto maior o tempo que a empresa estiver no mercado, mais opções e mais experiência ela terá no momento de aproveitar estes recursos.

Mattos (2017) examinou a relação entre utilidade esperada/valor esperado do planejamento tributário e o endividamento das empresas. Os resultados indicam que na maioria dos casos, mesmo com alta probabilidade de punição, o valor presente do planejamento tributário é positivo, podendo ser um forte motivador para este tipo de estratégia, o que explicaria o elevado número de provisões e passivos contingentes nas demonstrações financeiras e notas explicativas das empresas. Nessa mesma linha, Rezende (2015) encontrou correlação estatisticamente significa entre os passivos fiscais contingentes com os drives de criação de valore e destinação de valor. Estas constatações possibilitam conjecturar e estabelecer a seguinte hipótese:

Hipótese (H5): a presença de passivos fiscais contingentes constitui uma característica para a classificação das empresas na categoria daquelas que usufruem de subvenções e assistências governamentais.

A idade e o tamanho das empresas são considerados também características por Fonteles et al (2014) quando indica que [...] a respeito da análise do comportamento das SAG, montou-se um perfil das empresas beneficiárias de incentivos governamentais que são: empresas com maior tempo de mercado, menos alavancadas e com alta média de rentabilidade". Estas constatações possibilitam conjecturar e estabelecer a seguinte hipótese:

Hipótese (H6): a idade, ou tempo da empresa no mercado, constitui uma característica para a classificação das empresas na categoria daquelas que usufruem de subvenções e assistências governamentais.

Em relação a lucrativa de, Loureiro, Gallon e De Luca, (2011); De Luca e Lima (2007), e De Mendonça et al., (2013), consideram em suas pesquisas que analisa os efeitos econômicos e contábeis das Subvenções e Assistências Governamentais o tamanho e os indicadores financeiros e chegam à conclusão de que o recebimento de subvenções e assistências governamentais podem alterar os resultados econômicos auferidos e o capital próprio das empresas. De Luca e Lima (2007) acrescentam que para algumas empresas criou-se uma dependência dos benefícios fiscais, que a sua descontinuidade é risco a continuidade das operações da entidade.

Diante disso, levantou-se a seguinte hipótese: 
Hipótese (H7): a lucratividade constitui uma característica para a classificação das empresas na categoria daquelas que usufruem de subvenções e assistências governamentais.

Klemm e Van Parys (2012) analisaram, por meio de análises estatísticas, os dados incentivos fiscais de mais 40 países da América Latina, do Caribe e da África, entre 1985 a 2004. Eles constataram certa evidência de interação dentre as isenções fiscais e a taxa de imposto de renda imposta pelos países. Foram estudados certos incentivos fiscais, tais como os créditos fiscais à pesquisa e desenvolvimento e zonas empresariais de tratamento especial. Os autores indicam não ter achado evidência robusta no nível do país, mas, no contexto da efetividade destes incentivos ao nível das empresas beneficiárias, os autores ressaltam ainda que nenhum dos incentivos fiscais é eficaz em aumentar a formação bruta de capital fixo privado.

Esses resultados de não acumulação dos benefícios fiscais como ativos (investimentos operacionais) são aderentes aos resultados da pesquisa Rezende (2015), que identificou que as empresas mais beneficiadas são as que mais distribuem resultados. Isso demonstra que as subvenções não servem totalmente ao fomento das atividades econômicas locais (aumento da capacidade produtiva), mas cumpre um papel de remuneração disfarçada aos acionistas.

Adicionalmente, foi incorporada como variável o nível de governança corporativa. As práticas de governança corporativa, para Ramos e Martinez (2006), ajudam o relacionamento de todas as partes interessadas na organização, relacionamento que, de acordo com o Instituto Brasileiro de Governança Corporativa (IBGC), está representado por um sistema em que as empresas são monitoradas e incentivadas envolvendo a participação das partes interessadas, sócios, o conselho de administração, diretoria, os órgãos de fiscalização e as demais partes.

Para Silveira (2002), as empresas com uma estrutura de governança corporativa que esteja mais adequada às práticas recomendadas pelos agentes de mercado terão melhor valorização no mercado. Assim, levantou-se a seguinte hipótese:

Hipótese (H8): o nível de governança corporativa constitui uma característica para a classificação das empresas na categoria daquelas que usufruem de subvenções e assistências governamentais.

\section{PROCEDIMENTOS METODOLÓGICOS}

Foram analisadas 791 notas explicativas divulgadas nas demonstrações contábeis das empresas pesquisadas, obtidas junto ao site da Bm\&fBovespa. Esta análise documental foi determinante para a obtenção das informações sobre as políticas, a natureza e os valores contabilizados como subvenção pelas empresas. Após análise documental os dados analisados a partir de tratamento estatístico no software Stata, por meio da técnica de regressão logística.

A amostra pesquisada compreende 113 empresas listadas no Índice IBRX-100 da Bm\&fBovespa, no período de 2008 a 2014. Sekaran e Bougie (2009), este tipo de amostra é aquela que proporciona a mais vantajosa posição para proporcionar informação, já que compreende as empresas mais líquidas classificadas em diferentes setores econômicos.

\subsection{Modelo de Regressão Logística}

O modelo de regressão logística é obtido pelo procedimento de comparação da probabilidade de um evento ocorrer com a probabilidade de não ocorrer. Neste contexto, todas as empresas teriam a probabilidade de usufruir incentivos econômicos sempre que forem atingidos os requisitos necessários. Diante disso, a vantagem da regressão logística é que, ao empregar como variável dependente uma variável categórica (sim ou não), se precisarmos saber se um evento ocorrerá ou não a partir de um valor dicotômico (0 ou 1), consegue-se a estimativa de o evento ocorrer ou não (HAIR et al, 2005). Ainda, de acordo com Hair et al. (2005), a regressão logística pode ser utilizada na análise de problemas de pesquisas que envolvam uma variável dependente de natureza categórica ou não métrica e as variáveis independentes métricas. 
Foi utilizado o modelo estatístico de regressão logística para verificar se as características das empresas que usufruem benefícios fiscais são variáveis preditivas significantes. Ou seja, foi estimado neste modelo a probabilidade de uma empresa estar no grupo das que usufruem de subvenções governamentais por meio da função de probabilidade. Conforme apresentado na tabela abaixo, constata-se que há um número significativo que usufruem de algum tipo de benefícios fiscais.

Tabela 1 - Número de observações de empresas que possuem subvenções

\begin{tabular}{|c|c|c|c|c|}
\hline & \multicolumn{4}{|c|}{ Subvenções Estaduais } \\
\hline & & 0 & 1 & Total \\
\hline \multirow{3}{*}{ Subvenções Federais } & 0 & 451 & 62 & 513 \\
\hline & 1 & 278 & 0 & 278 \\
\hline & Total & 729 & 62 & 791 \\
\hline
\end{tabular}

Fonte: dados da pesquisa

Para a operacionalização destes construtos no modelo logístico, foram utilizadas variáveis independentes e de controle para predizer a classificação das empresas que possuem subvenções governamentais - variável dependente, sendo 0 (zero) para as que não declaram ter subvenção e 1 (um) para as que declaram ter subvenção, em algum dos períodos analisados, portanto, trata-se de um problema multivariável.

A medida de associação calculada, a partir do modelo logístico, foi o odds ratio (razão de chances). $\mathrm{O}$ modelo de regressão logístico proposto foi o seguinte:

$$
\begin{aligned}
& S U B V_{i t}=\beta_{0}+\beta_{1} R O A_{i t}+\beta_{2} L N A T I V O_{i t}+\beta_{3} I F R S_{i t}+\beta_{4} A u d_{-} B I G 4_{i t}++\beta_{5} C_{-} \text {ter } i t \\
& +\beta_{6} B N D E S_{i t}+\beta_{7} P P R O V_{i t}+\beta_{8} P P S S V_{i t}+\beta_{9} P R E M_{i t}+\beta_{10} I D A D_{i t}
\end{aligned}
$$

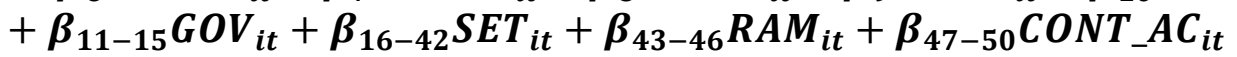

$$
\begin{aligned}
& +\beta_{51-53} R E G_{i t}+\varepsilon_{i t}
\end{aligned}
$$

Em que:

$\boldsymbol{S} \boldsymbol{U} \boldsymbol{B} \boldsymbol{V}_{i t}=$ Variável dummy, assumindo valor igual a 1 (um) se empresa divulga ter algum tipo de subvenção governamental (benefícios fiscais) e 0 (zero) caso contrário.

$\boldsymbol{D}_{-} \boldsymbol{G O} \boldsymbol{V}_{\boldsymbol{i t}}=$ variável dummy, assumindo valor igual a 1 (um) quando a empresa pertencer a algum nível de Governança Corporativa da BM\&FBOVESPA (Nível 1, Nível 2 ou Novo Mercado) e valor igual a 0 (zero) quando a empresa não pertencer a nenhum nível da BM\&FBOVESPA. $\boldsymbol{R O} \boldsymbol{A}_{i t}=$ taxa de retorno sobre os ativos da empresa i no ano $\mathrm{t}$.

Ln_Ativo total $_{\text {it }}=$ como medida de tamanho utilizou o logaritmo natural do ativo total da empresa i no ano t.

$\boldsymbol{I F} \boldsymbol{R} \boldsymbol{S}_{\boldsymbol{i t}}=$ utilizou como variável dummy para antes e depois da adoção de IFRS pelas empresas, sendo 0 (zero) para os anos de 2008 e 2009 e 1 (um) para os demais períodos para cada empresa i no ano t.

Aud_BIG4 $\boldsymbol{A}_{i t}$ = variável dummy, assumindo valor igual a 1 (um) quando a empresa foi auditada por uma empresa de auditoria BIG4.

$\boldsymbol{C}_{-} \boldsymbol{t e} \boldsymbol{r}_{i t}=$ custo de capital de terceiros da empresa i no ano t.

$\boldsymbol{B N D E}_{\boldsymbol{i t}}=$ variável dummy, assumindo valor igual a 1 (um) quando a empresa declarou tem captado recursos junto ao BNDES.

$\boldsymbol{P P R O V} \boldsymbol{V}_{i t}=$ valor da provisão fiscal de contingência classificada como provável dividido pelo ativo total da empresa i no ano t.

$\boldsymbol{P P S S V}_{i t}=$ valor da provisão fiscal de contingência classificada como possível dividido pelo ativo total da empresa i no ano t.

$\boldsymbol{P R E} \boldsymbol{M}_{i t}=$ valor da provisão fiscal de contingência classificada como remota dividido pelo ativo total da empresa i no ano t.

$\boldsymbol{I D A D} \boldsymbol{E}_{\boldsymbol{i}}=$ ano de fundação da empresa menos data na coleta dos dados da empresa i no ano t. 
$\boldsymbol{D}_{\mathbf{G}} \boldsymbol{G O} \boldsymbol{V}_{\boldsymbol{i t}}=$ variável dummy, assumindo valor igual a 1 (um) quando a empresa pertencer a algum nível de Governança Corporativa da BM\&FBOVESPA (Nível 1, Nível 2 ou Novo Mercado) e valor igual a 0 (zero) quando a empresa não pertencer a nenhum nível da BM\&FBOVESPA

$\boldsymbol{S E T}_{i t}=$ variável dummy, assumindo valor igual a 1 (um) quando a empresa pertencer a algum setor e atribui o valor igual a 0 (zero) para os demais.

$\boldsymbol{R} \boldsymbol{A} \boldsymbol{M}_{i t}$ = variável dummy, assumindo valor igual a 1 (um) quando a empresa pertencer a algum ramo (agronegócio, serviços, indústria ou comércio) e atribui o valor igual a 0 (zero) para os demais.

CONTA $\boldsymbol{C}_{\boldsymbol{i t}}=$ variável dummy, assumindo valor igual a 1 (um) quando a empresa pertencer a um tipo de controle acionário (público e estrangeiro) e atribui o valor igual a 0 (zero) para os demais.

$\boldsymbol{R} \boldsymbol{E} \boldsymbol{G}_{\boldsymbol{i t}}$ = variável dummy, assumindo valor igual a 1 (um) quando a empresa estiver instalada em alguma das regiões brasileiras (Sudeste, Sul, Centro-oeste, Nordeste e Norte) e atribui o valor igual a 0 (zero) para os demais.

$\boldsymbol{\varepsilon}_{i t}=$ erro aleatório para a empresa i no ano t.

\section{RESULTADOS E DISCUSSÃO}

Nas análises das notas explicativas foram identificadas que 48 empresas (43\% da amostra), usufruíram de algum tipo de subvenção ou assistência governamental, totalizando aproximadamente

Tabela 2 - Valor de Subvenções recebido pelas empresas da amostra por ano

\begin{tabular}{cc}
\hline ANO & VALOR \\
\hline 2008 & 3.806 .230 \\
2009 & 4.308 .713 \\
2010 & 2.660 .163 \\
2011 & 3.391 .357 \\
2012 & 3.519 .233 \\
2013 & 6.057 .898 \\
2014 & 6.203 .390 \\
\hline TOTAL & $\mathbf{2 9 . 9 4 6 . 9 8 4}$ \\
\hline
\end{tabular}

Fonte: Dados da pesquisa.

R\$ 30 bilhões, sendo que os períodos de 2013 e 2014 foram destaques, conforme demonstrado na Tabela abaixo.

Os tipos de subvenção ou assistência governamental identificados foram os seguintes:

Destinados ao setor elétrico: PROINFA - Programa de Incentivo a Fontes Alternativas de Energia.

Empréstimos Subsidiados do Banco Nacional de Desenvolvimento Econômico e Social (BNDES); e FINAME - Financiamento de máquinas e equipamentos

Pesquisa e Desenvolvimento: FINEP- Fundo de Financiamento de Estudos de Projetos e Programas. Fundos de Desenvolvimento Regional: FAIN - Fundo de Apoio ao Desenvolvimento Industrial da Paraíba, FINAM - Fundo de Investimentos da Amazônia, FINOR - incentivos físcais do Fundo de Investimento do Nordeste, FUNDOPEM/RS - Fundo Operação Empresa do Estado do Rio Grande do Sul , PRODEPE - Programa de Desenvolvimento de Pernambuco, PRODES - Programa de Despoluição de Bacias Hidrográficas, PRODESIN -Programa de Desenvolvimento Integrado do Estado de Alagoas.

Incentivos fiscais destinados a projetos de caráter social: PROUNI - Programa Universidade para Todos, PAT - Programas de Alimentação do Trabalhador, Incentivos Fiscais - Lei de Incentivo à Cultura, Incentivos Fiscais de Atividade Audiovisual, PRONON - Programa Nacional de Apoio à Atenção Oncologia, Incentivos Fiscais-Fundos do Direito da Criança e do Adolescente, Lei do Idoso, Programa Nacional de Apoio à Atenção da Saúde da Pessoa com Deficiência.

Outros: Crédito-prêmio de IPI

Na Tabela 3, observa-se que $44 \%$ das empresas usufruíram de algum tipo de incentivo e estavam localizadas no Estado de São Paulo, Estado est que por sua vez concentra 51\% da amostra, 
com o recebimento de aproximadamente $\mathrm{R} \$ 13.034$ (bilhões); seguido pelos Estados de Bahia com R\$ 3.277(bilhões); Rio de Janeiro com R\$ 3.178(bilhões); Minas Gerais com R\$ 2.941(bilhões), Goiás com R \$ 2.253(bilhões) e Santa Catarina com R \$ 1.967(bilhões). Nos demais Estados foram identificados empresas que também usufruem de subvenções governamentais, embora em menor proporção.

Tabela 3 - Valor da SAGS recebida declarada em nota explicativa (em Bilhões de reais)

\begin{tabular}{ccc}
\hline ESTADO & $\%$ & VALOR DA SAGS \\
\hline BAHIA & $10,94 \%$ & 3.277 .513 \\
CEARÁ & $3,86 \%$ & 1.154 .754 \\
GOIÁS/BRAŚ́LIA & $7,52 \%$ & 2.252 .584 \\
MARANHÃO & $1,36 \%$ & 408.227 \\
MINAS GERAIS & $9,82 \%$ & 2.941 .396 \\
PARANÁ & $2,47 \%$ & 739.723 \\
PERNAMBUCO & $0,25 \%$ & 75.288 \\
RIO DE JANEIRO & $10,61 \%$ & 3.178 .419 \\
RIO GRANDE DO SUL & $3,06 \%$ & 917.496 \\
SANTA CATARINA & $6,57 \%$ & 1.967 .750 \\
SÃO PAULO & $43,52 \%$ & 13.033 .834 \\
\hline TOTAL & $100 \%$ & 29.946 .984 \\
\hline
\end{tabular}

Fonte: Dados da pesquisa.

Tabela 4 - Empresas que obterem Empréstimos junto ao BNDES

\begin{tabular}{ccc}
\hline BNDES & N. Obs. & N. de Empresas \\
\hline 0 & 304 & 43 \\
1 & 487 & 70 \\
\hline Total & $\mathbf{7 9 1}$ & $\mathbf{1 1 3}$ \\
\hline
\end{tabular}

Fonte: dados da pesquisa

Conforme apresentado na Tabela 4, do total de 113 empresas, apenas 43 empresas (38\% da amostra), indicaram não ter obtido, em nenhum momento do período estudado, algum financiamento do BNDES. Entretanto a maior parte da amostra, 70 empresas que representam $68 \%$ informaram em suas demonstrações contábeis ter obtido algum empréstimo ou financiamento junto ao BNDES, financiamentos com juros subsidiados que representa um tipo de subvenção conforme o CPCP 07.

$\mathrm{Na}$ Tabela 5 são apresentadas as estatísticas descritivas referente as variáveis utilizadas no modelo de regressão logística.

Tabela 5 - Estatística Descritiva

\begin{tabular}{cccccc}
\hline Variáveis & Observações & Média & Desvio Padrão & Min & Max \\
\hline SUBV & 791 & 0.456 & 0.498 & 0 & 1 \\
ROA & 785 & 0.422 & 2.110 & -2.5 & 2.5 \\
Lnativ & 777 & 15.804 & 2.066 & 1.6 & 21.0 \\
IFRS & 791 & 0.714 & 0.452 & 0 & 1 \\
Aud_Big4 & 791 & 0.912 & 0.284 & 0 & 1 \\
IDAD & 791 & 39.4 & 33.5 & 3.0 & 207.0 \\
BNDES & 791 & 0.616 & 0.487 & 0 & 1 \\
PPROV & 777 & 0.021 & 0.136 & -0.00 & 2.55 \\
PPSS & 777 & 0.049 & 0.264 & -0.02 & 5.47 \\
PREM & 777 & 0.056 & 0.273 & -0.02 & 5.47 \\
C_TER & 777 & 0.094 & 0.389 & -0.23 & 8.91 \\
\hline
\end{tabular}

Fonte: dados da Pesquisa

Na Tabela 6, observa-se que 59\% das observações são de empresas listadas no Nível de Governança Corporativa do "Novo Mercado", nível representado pelas empresas que adotaram o mais alto nível de governança, sendo companhias comprometidas voluntariamente em adotar todas 
as práticas e exigências da legislação, sendo empresas que desejam sinalizar maior transparência de suas operações no mercado.

Tabela 6 - Número de observações por nível de governança corporativa - 2008 a 2014

\begin{tabular}{cccc}
\hline Nível de Governança Corporativa & Freq. & Percentual & Cumulativo. \\
\hline Novo Mercado & 469 & 59.29 & 59.29 \\
Não segmentada & 35 & 4.42 & 63.72 \\
Nível 1 & 140 & 17.7 & 81.42 \\
Nível 2 & 56 & 7.08 & 88.5 \\
Tradicional Bov & 91 & 11.5 & 100 \\
\hline Total & $\mathbf{7 9 1}$ & $\mathbf{1 0 0}$ &
\end{tabular}

Fonte: dados da Pesquisa.

A adoção das normas internacional de contabilidade institui normativo específico para o tratamento das subvenções governamentais de acordo com o Pronunciamento Técnico Contábil 07. Este pronunciamento demanda que as empresas deem maior publicidade contábil, aos valores de subvenções usufruídas, nos respectivos períodos. Assim, utilizou como variável dummy o processo de adoção de IFRS como variável de controle (antes e depois da adoção completa), conforme pode ser observado na Tabela 7, 71.43\% das observações da amostra se concentram no período pós adoção IFRS.

Tabela 7 - Número de observações antes e depois da adoção de IFRS (2008 a 2014)

\begin{tabular}{ccc}
\hline IFRS & Frequência & Percentual \\
\hline Antes & 226 & 28.57 \\
Depois & 565 & 71.43 \\
\hline Total & $\mathbf{7 9 1}$ & $\mathbf{1 0 0}$ \\
\hline
\end{tabular}

Fonte: Dados da Pesquisa.

Os resultados do modelo de regressão logística, apresentados na tabela 8, demonstram resultados robustos e satisfatória, pois o modelo classificou corretamente $77,84 \%$ das observações analisadas. Esses resultados obtidos demonstram uma validade aparente para o modelo proposto. Adicionalmente, pode-se afirmar que as variáveis utilizadas no modelo possuem poder explicativo, em termos de chances para classificar as empresas na categoria que usufruem subvenções e assistências governamentais.

Tabela 8 - Modelo logístico

\begin{tabular}{|c|c|c|c|}
\hline Classified & Subv (D) & $\tilde{\mathbf{N}} \operatorname{Subv}(\sim \mathbf{D})$ & Total \\
\hline$+\mid \mathrm{D}$ & 239 & 65 & 304 \\
\hline$-\mid \sim D$ & 101 & 344 & 445 \\
\hline Total & 340 & 409 & 749 \\
\hline Sensitivity & $\operatorname{Pr}(+\mid \mathrm{D})$ & & $70.29 \%$ \\
\hline Specificity & $\operatorname{Pr}(-\mid \sim \mathrm{D})$ & & $84.11 \%$ \\
\hline Positive predictive value & $\operatorname{Pr}(\mathrm{D} \mid+)$ & & $78.62 \%$ \\
\hline Negative predictive value & $\operatorname{Pr}(\sim \mathrm{D} \mid-)$ & & $77.30 \%$ \\
\hline False + rate for true $\sim D$ & $\operatorname{Pr}(+\mid \sim \mathrm{D})$ & & $15.89 \%$ \\
\hline False - rate for true D & $\operatorname{Pr}(-\mid D)$ & & $29.71 \%$ \\
\hline False + rate for classified + & $\operatorname{Pr}(\sim \mathrm{D} \mid+)$ & & $21.38 \%$ \\
\hline False - rate for classified - & $\operatorname{Pr}(\mathrm{D} \mid-)$ & & $22.70 \%$ \\
\hline Correctly classified & & & $77.84 \%$ \\
\hline
\end{tabular}

Fonte: dados da Pesquisa

Na Tabela 9, apresenta-se os resultados obtidos com a aplicação do modelo de regressão Logística e relevância estatísticas de cada variável testadas. 
Tabela 9 - Resultados da Regressão Logística

\begin{tabular}{|c|c|c|c|c|c|c|}
\hline Subv & Odds Ratio & $\begin{array}{l}\text { Robust } \\
\text { Std. Err. }\end{array}$ & $\mathbf{z}$ & $\mathbf{P}>|\mathbf{z}|$ & [95\% Conf. & Interval] \\
\hline Roa & 26.551 & 52.162 & 1.67 & $0.0950 *$ & 0.565 & 1248.323 \\
\hline Lnativ & 1.346 & 0.137 & 2.91 & $0.0040 *$ & 1.102 & 1.644 \\
\hline IFRS & 2.105 & 0.483 & 3.25 & $0.0010 * * *$ & 1.344 & 3.299 \\
\hline AUD_Big4 & 12.962 & 15.170 & 2.19 & $\mathbf{0 . 0 2 9 0} * *$ & 1.308 & 128.492 \\
\hline IDAD & 0.996 & 0.005 & -0.73 & 0.4670 & 0.987 & 1.006 \\
\hline BNDES & 1.745 & 0.456 & 2.13 & $0.0330 * *$ & 1.045 & 2.913 \\
\hline PPROV & 2.093 & 1.708 & 0.9 & 0.3660 & 0.423 & 10.361 \\
\hline PPSS & 0.032 & 0.078 & -1.43 & 0.1530 & 0.000 & 3.576 \\
\hline PREM & 54.225 & 128.995 & 1.68 & $0.0930 *$ & 0.512 & 5742.503 \\
\hline C_TER & 1.057 & 0.258 & 0.23 & 0.8190 & 0.656 & 1.705 \\
\hline Dgov1 & 1.483 & 0.524 & 1.11 & 0.2650 & 0.742 & 2.965 \\
\hline Dgov2 & 1.193 & 0.719 & 0.29 & 0.7700 & 0.366 & 3.885 \\
\hline Dgov3 & 0.925 & 0.465 & -0.16 & 0.8760 & 0.345 & 2.478 \\
\hline Dgov5 & 0.694 & 0.330 & -0.77 & 0.4420 & 0.274 & 1.760 \\
\hline Dset1 & 0.007 & 0.013 & -2.68 & $0.0070 * * *$ & 0.000 & 0.262 \\
\hline Dset2 & 0.063 & 0.104 & -1.67 & 0.0950* & 0.002 & 1.616 \\
\hline Dset4 & 0.008 & 0.011 & -3.74 & $0.0000 * * *$ & 0.001 & 0.103 \\
\hline Dset6 & 0.003 & 0.005 & -3.37 & $0.0010 * * *$ & 0.000 & 0.085 \\
\hline Dset8 & 0.013 & 0.018 & -3.22 & $0.0010 * * *$ & 0.001 & 0.185 \\
\hline Dset9 & 0.012 & 0.014 & -3.78 & $0.0000 * * *$ & 0.001 & 0.120 \\
\hline Dset10 & 0.014 & 0.021 & -2.73 & $0.0060 * * *$ & 0.001 & 0.296 \\
\hline Dset11 & 0.044 & 0.054 & -2.56 & $0.0100 * * *$ & 0.004 & 0.481 \\
\hline Dset12 & 0.035 & 0.046 & -2.53 & $\mathbf{0 . 0 1 1 0} * *$ & 0.003 & 0.470 \\
\hline Dset13 & 0.206 & 0.324 & -1.01 & 0.3140 & 0.010 & 4.465 \\
\hline Dset15 & 0.027 & 0.032 & -3.03 & $0.0020 * * *$ & 0.003 & 0.277 \\
\hline Dset16 & 0.269 & 0.454 & -0.78 & 0.4360 & 0.010 & 7.334 \\
\hline Dset17 & 0.409 & 0.555 & -0.66 & 0.5100 & 0.029 & 5.846 \\
\hline Dset18 & 0.038 & 0.047 & -2.65 & $0.0080 * * *$ & 0.003 & 0.427 \\
\hline Dset19 & 0.034 & 0.044 & -2.65 & $0.0080 * * *$ & 0.003 & 0.416 \\
\hline Dset20 & 0.605 & 0.995 & -0.31 & 0.7600 & 0.024 & 15.193 \\
\hline Dset21 & 0.050 & 0.089 & -1.69 & $0.0920 *$ & 0.002 & 1.625 \\
\hline Dset22 & 0.035 & 0.051 & -2.28 & $\mathbf{0 . 0 2 3 0} * *$ & 0.002 & 0.623 \\
\hline Dset23 & 0.009 & 0.011 & -3.66 & $0.0000 * * *$ & 0.001 & 0.111 \\
\hline Dset24 & 0.023 & 0.031 & -2.78 & $0.0050 * * *$ & 0.002 & 0.329 \\
\hline Dset25 & 0.642 & 1.416 & -0.2 & 0.8410 & 0.009 & 48.350 \\
\hline Dset26 & 0.819 & 1.372 & -0.12 & 0.9050 & 0.031 & 21.883 \\
\hline Dram2 & 2.397 & 1.364 & 1.54 & 0.1240 & 0.786 & 7.315 \\
\hline Dram3 & 0.853 & 0.482 & -0.28 & 0.7780 & 0.282 & 2.582 \\
\hline Dram4 & 1.567 & 1.136 & 0.62 & 0.5350 & 0.379 & 6.490 \\
\hline Dcontac1 & 7.188 & 4.368 & 3.25 & $0.0010 * * *$ & 2.185 & 23.649 \\
\hline Dcontac3 & 2.156 & 1.693 & 0.98 & 0.3280 & 0.462 & 10.051 \\
\hline Dreg1 & 3.026 & 3.429 & 0.98 & 0.3280 & 0.328 & 27.882 \\
\hline Dreg2 & 0.779 & 0.588 & -0.33 & 0.7400 & 0.177 & 3.425 \\
\hline Dreg3 & 0.132 & 0.057 & -4.68 & $0.0000 * * *$ & 0.057 & 0.309 \\
\hline \multicolumn{3}{|c|}{ Number of obs. } & \multicolumn{4}{|c|}{749.000} \\
\hline \multicolumn{3}{|c|}{ LR chi2(44) } & \multicolumn{4}{|c|}{157.94} \\
\hline \multicolumn{3}{|c|}{ Prob > chi 2} & \multicolumn{4}{|c|}{$0.00000 * * *$} \\
\hline \multicolumn{3}{|c|}{ Pseudo R2 } & \multicolumn{4}{|c|}{0.2947} \\
\hline \multicolumn{3}{|c|}{ Log likelihood } & \multicolumn{4}{|c|}{-363.9145} \\
\hline
\end{tabular}

Nota: $\mathrm{O}(\mathrm{s})$ asterisco(s) indica(m) o nível de significância do coeficiente: $* * *(1 \%), * *(5 \%)$ e $*(10 \%)$.

No total foram necessárias a realização de 16 iterações para estimar o modelo, sendo que este se demonstrou significativo ao nível de 1\%, o Pseudo R2 é de, aproximadamente, 29,47\% da variação da variável dependente (SUBV) pode ser explicada pelas variáveis independentes do modelo. 
Na tabela 9, observa-se que as variáveis Idade das empresas (IDAD), provisões contingentes fiscais classificadas como provável (PPROV) e possível (PPSSV), custo do capital de terceiros (C_TER) e o nível de governança corporativa (GOV), não foram significativas.

Observa-se que os setores de bebidas, energia elétrica, maquinarias e equipamentos, telecomunicação, consumo cíclico e não cíclico, bens industriais-serviços, materiais, transporte e metalúrgica, químicos seguros e tecnologia da informação constam como os setores econômicos que mais fazem uso de subvenções, ou assistências governamentais.

Para análise dos resultados, calculou-se a probabilidade de ocorrência, a partir do Odds Ratio (razão de chances), conforme demonstrado na Tabela 10.

Tabela 10 - Probabilidade de Ocorrência

\begin{tabular}{ccc}
\hline SUBV & Odds Ratio & (OR-1)*100 \\
\hline Roa & 26.55 & 2555.14 \\
Lnativ & 1.35 & 34.58 \\
IFRS & 2.11 & 110.54 \\
AUD_Big4 & 12.96 & 1196.24 \\
IDAD & 1.00 & \\
BNDES & 1.74 & 74.47 \\
PPROV & 2.09 & \\
PPSS & 0.03 & 5322.55 \\
PREM & 54.23 & \\
C_TER & 1.06 & 618.83 \\
CONT_AC & 7.19 & \\
\hline
\end{tabular}

Fonte: dados da Pesquisa

Diante dos dados apresentados, pode-se observar que:

- As empresas mais lucrativas (ROA) têm mais chances de ser classificadas no grupo "Usufruem Subvenções Governamentais", 2.555,13\% maior do que uma empresa menos lucrativa.

- O tamanho da empresa (LnAtivo) impacta 34,58\% a mais nas chances de a empresa ser classificada no grupo "Usufruem Subvenções Governamentais", comparativamente com as menores.

- A adoção de IFRS impactou 110,54\% nas chances de a empresa ser classificada no grupo "Usufruem de Subvenções Governamentais", comparativamente antes da adoção de IFRS. Esse resultado comprova que as empresas foram obrigadas a dar maior publicidade para as subvenções que usufruem.

- A empresa ser auditada por uma firma de Auditoria BIG4 impacta 1.196,24\% nas chances de ela usufruir e evidenciar as subvenções governamentais.

- A empresa possuir recursos captados junto ao BNDES impacta 74,47\% a mais nas chances de a empresa ser classificada no grupo "Usufruem Subvenções Governamentais", comparativamente com as que não possuem financiamento.

- As empresas que possuem provisões contingentes fiscais classificadas como "remotas", evidenciadas nas notas explicativas, impacta 5.322,55\% a mais nas chances de a empresa ser classificada no grupo "Usufruem Subvenções Governamentais", comparativamente com as que não possuem.

- A empresa possuir controle acionário privado impacta $618,83 \%$ a mais nas chances de a empresa ser classificada no grupo "Usufruem Subvenções Governamentais", comparativamente com as de controle estatal ou estrangeiro.

Os resultados das variáveis relacionado as "Provisões Contingentes Fiscais" e "Controle Acionário (privado)" demonstram que há uma chance de haver maior agressividade tributária por parte dos gestores destas empresas. 


\section{CONSIDERAÇÕES FINAIS}

Acredita-se que o fato de a empresa usufruir de benefícios fiscais está relacionado à atividade da empresa, que aumenta a chance desta empresa ser classificada no grupo de beneficiários de subvenções, isso indica que a oportunidade de usufruir subvenções e assistências governamentais é maior para as empresas de determinados setores, a exemplo do setor elétrico. Esses resultados são corroborados por De Mendonça et al (2013) que também constataram que as empresas do setor elétrico foram as que mais receberam apoio econômico do governo.

Comparando os resultados desta pesquisa com as evidências da literatura (BENETTI et al., 2014; CRISPIM, 2011; DE MENDONÇA et al., 2013; DOS SANTOS; DANI; KLANN, 2015; LOUREIRO; GALLON; DE LUCA, 2011; REZENDE 2015, TAVEIRA, 2009) pode-se afirmar que efetivamente que existe uma relação estatística positiva entre: recebimento de subvenções e assistências governamentais com a adoção de IFRS, tamanho da empresa, se auditada por Big4, possuir financiamentos de bancos Públicos (Ex. BNDES), possuir controle acionário privado e apresentar valores provisionados em contingências fiscais. Portanto, as hipóteses estabelecidas na pesquisa foram estatisticamente confirmadas, a partir da classificação probabilística utilizada, são elas: adoção de IFRS (CPC 07), Presença de Contingências Fiscais (Possíveis, Prováveis, Remotas), Grau de Lucratividade, Tamanho da Empresa, ser auditada por grandes Empresas de Auditoras (Big4) e ter Controle Acionário privado.

No entanto, não foi possível confirmar o impacto do Custo de Capital de Terceiros, a presença de Contingências Fiscais (Possíveis, Prováveis), Idade da Empresa, e o Nível de Governança Corporativa na classificação da empresa no grupo de empresas que beneficiam de subvenções governamentais.

Dentre os tipos de incentivos identificados como subvenção identificou as seguintes modalidades: i) redução porcentual de ICMS; ii) redução da alíquota de IRPJ; iii) programas de desenvolvimento industrial, por exemplo os benefícios financeiros oferecidos ao setor elétrico; iv) empréstimos e financiamentos de Bancos Públicos (Ex. BNDES); v) incentivos para pesquisa e desenvolvimento; e vi) Fundos de Desenvolvimento Regional e industrial.

Como sugestão para futuras pesquisas, sugere-se

i) Avaliar o impacto econômico destas subvenções e assistências governamentais, por regiões e as externalidades produzidas em termos de transferência de rendas e ganhos econômicos e sociais;

ii) Ampliar o número de empresas nas analises, tais como S/A fechadas, limitadas, a fim de comprovar se características identificadas como significantes são determinantes para classificação das empresas no grupo das que usufruem dos programas de subvenções; e

iii)Investigar a efetividade do retorno das subvenções concedidas por meio de estudos analíticos (ex. estudos de casos), com o intuito de avaliar a eficácia da política industrial adotadas nas últimas décadas pelos governos brasileiros tanto no nível nacional ou regional.

Dentre as limitações desta pesquisa, destaca-se que os resultados obtidos devem ficar restritos apenas as empresas analisadas, não permitindo a realização de generalizações. Além disso, os resultados são de empresas de capital aberto, listadas na BMF\&BOVESPA e não possibilita a realização de inferências sobre as características identificadas para as empresas fechadas e/ou limitadas.

\section{REFERENCIAS}

Baltagi, B. (2008). Econometric analysis of panel data. John Wiley \& Sons.

Baghana, R., \& Mohnen, P. (2009). Effectiveness of R\&D tax incentives in small and large enterprises in Québec. Small Business Economics, 33(1), 91-107. 
Bartik, T. J. (2005). Solving the problems of economic development incentives. Growth and Change, 36(2), 139-166.

Benetti, K., Benetti, K., Utzig, M. J. S., Braun, M., \& Oro, L. M. (2014). Evidenciação de subvenção e assistência governamentais das empresas na BM\&FBOVESPA. Revista Evidenciação Contábil \& Finanças, 2(1), 75-90.

Bernardo, D. C. R., Nascimento, J. P. B., Salazar, G. T., Vale, C. R., Vilas Boas, A. A., \& Mendonça, F. M. (2010). Políticas de incentivos fiscais federais: um "jeitinho brasileiro" de estimular as práticas de responsabilidade social? In Anais, XXXIV Encontro da ANPAD, Rio de Janeiro.

Bergamaschi, E. A. (2009). Inovação tecnológica e incentivos fiscais no setor de serviços de telecomunicações (Dissertação de Mestrado). Universidade Federal do Rio Grande do Sul. Programa de Pós-Graduação em Administração, Porto Alegre.

Bérubé, C., \& Mohnen, P. (2009). Are firms that receive R\&D subsidies more innovative? Canadian Journal of Economics/Revue canadienne d'économique, 42(1), 206-225.

Brasil, Bolsa e Balcão (2014). Metodologia do índice Brasil 100 (IBrX 100). Acesso em: $<$ http://www.bmfbovespa.com.br/lumis/portal/file/fileDownload.jsp?fileId=8A828D29514A32670151 6E6C30E76F87>

Bondonio, D., \& Greenbaum, R. T. (2007). Do local tax incentives affect economic growth? What mean impacts miss in the analysis of enterprise zone policies. Regional Science and Urban Economics, 37(1), 121-136.

Brasil. Lei n ${ }^{\circ}$ 4.320, de 17 de março de 1964. Estatui Normas Gerais de Direito Financeiro para elaboração e contrôle dos orçamentos e balanços da União, dos Estados, dos Municípios e do Distrito Federal. 1964. Disponível em: <http://www.planalto.gov.br/ccivil_03/leis/L4320compilado.htm〉. Acesso em: 20 ago. 2015.

Brasil. Lei $\mathrm{n}^{\circ}$ 6.404, de 15 de dezembro de 1976. Dispõe sobre as Sociedades por Ações. 1976. Disponível em: <http://www.planalto.gov.br/ccivil_03/leis/16404consol.htm>.

Brasil. Constituição (1988). Constituição da República Federativa do Brasil. Brasília, DF: Senado, 1988. Disponível

em: <http://www.senado.gov.br/legislacao/const/con1988/CON1988_04.02.2010/art_174_.shtm>.

Ministério da Fazenda. Secretaria da Receita Federal (2000). Considerações gerais sobre incentivos. Disponível em: <http://www.receita.fazenda.gov.br/pessoajuridica/dipj/2000/orientacoes/ConsideracoesGeraissobreIn centivos.htm\#reinvestimento>

Lei $\mathrm{n}^{\circ}$ 11.196, de 21 de novembro de 2005. Institui o Regime Especial de Tributação para a Plataforma de Exportação de Serviços de Tecnologia da Informação - REPES, o Regime Especial de Aquisição de Bens de Capital para Empresas Exportadoras - RECAP e o Programa de Inclusão Digital. 2005. Disponível em: <http://www.planalto.gov.br/ccivil_03/_ato2004-2006/2005/lei/111196.htm>

Ministério de Ciência, Tecnologia e Inovação (2012). Informações gerais. Disponível em: <http://www.mct.gov.br/index.php/content/view/6067/Informacoes_Gerais.html>

Ministério da Ciência, Tecnologia e Inovação (2013). Relatório anual da utilização dos incentivos fiscais ano base 2012. Brasília, DF.

Busom, I. B., Martínez-Azúa, B. C., \& Ros, E. M. (2015). ¿ Todos los caminos llevan a Roma? Incentivos fiscales, ayudas directas y la inversión empresarial en I+ D. Ekonomiaz: Revista Vasca de Economía, (88), 262-281..

Campanelli, D. M. (2010) Incentivos fiscais estaduais concedidos unilateralmente e segurança jurídica (Mestrado em Direito do Estado). Pontifícia Universidade Católica de São Paulo, Programa de PósGraduação em Direito do Estado, São Paulo.

Campana, N. A. C., \& Almeida, F. M. (2010). Aula Prática No 3 - "Dados em Painel". ERU 626 Econometria I: Universidade Federal de Viçosa.

Cardoso Júnior, J. C. C. (2010). Prioridade ao combate à desigualdade social. In: Cardoso Júnior, J. C. C. (2010). Brasil em desenvolvimento: estado, planejamento e políticas públicas. Brasília: Ipea, 3, p. 237-508.

Cerqueira, D. F. (2007). Incentivos fiscais e investimentos na indústria de transformação no estado de Bahia (1994 a 2004): internacionalização produtiva e subdesenvolvimento (Mestrado em Ciências Contábeis). Universidade de Campinas, Programa de Pós-Graduação em Ciências Contábeis, Campinas. 
Comitê de Pronunciamentos Contábeis. (2010). CPC 07 (R1): Subvenções e Assistências Governamentais. Aprovado na Deliberação CVM No 646, (2010, 02 de dezembro), que revoga o CPC 07 Aprovado pela Deliberação $\mathrm{CVM} \mathrm{n}^{\circ}$ 555, (2008,12 de novembro).

Chagas, M. J. R., Damascena, L. G., Alves, K. R. C. P., \& Queiroz, D. B. (2010). Evidenciação das Subvenções e Assistências Governamentais recebidas pelas OSCIPs: uma análise empírica nos estados da Paraíba e do Rio Grande do Norte. In Anais, $13^{\circ}$ Seminários em Administração, São Paulo. São Paulo: SemeAD.

Chirinko, R. S., \& Wilson, D. J. (2008). State investment tax incentives: A zero-sum game? Journal of Public Economics, 92(12), 2362-2384.

Crispim, G. (2011). Subvenção governamental sob a ótica do CPC 07: reconhecimento contábil após a Lei 11.638/2007 nas entidades privadas no Estado de Pernambuco (Dissertação de Mestrado). Universidade Federal de Pernambuco, Programa de Pós-Graduação em Ciências Contábeis, Recife.

Danielova, A., \& Sarkar, S. (2011). The effect of leverage on the tax-cut versus investment-subsidy argument. Review of Financial Economics, 20(4), 123-129.

de Mendonça Julião, C., Lagioia, U. C. T., de Assis Carlos Filho, F., de Araújo, J. G., da Silva Filho, L. L., \& Silva, I. É. M. (2013). Um estudo sobre a correlação entre o recebimento de subvenções governamentais e o lucro das empresas nacionais, e das maiores internacionais, do setor elétrico. Revista Uniabeu, 6(14), 173-189.

De Luca, M. M. M., \& Lima, V. F. L. (2007). Efeito dos incentivos fiscais no patrimônio das entidades beneficiárias do programa FDI, do governo do estado do Ceará. Contextus-Revista Contemporânea de Economia e Gestão, 5(1).

dos Santos, A. C., Dani, A. C., \& Klann, R. C. (2015). Análise da evolução da divulgação dos requisitos do CPC 07 por empresas reguladas do setor elétrico listadas na BM\&FBOVESPA. Registro Contábil, 6(2), 91-108.

ERNST\&YOUNG, FIPECAFI. (2009). Manual de Normas Internacionais de Contabilidade: IFRS versus normas brasileiras. São Paulo: Atlas.

Amaral Filho, J. D. (2010). Incentivo fiscal como instrumento de desenvolvimento local ou regional. Revista Desenbahia, 2(1), 07-38.

Fonteles, I. V., Ponte, V. M. R., Oliveira, M. C., \& Ribeiro, M. S. (2014). Fatores determinantes da evidenciação socioambiental sob o enfoque do recebimento de assistências governamentais. In Anais, $8^{\circ}$ Congresso da ANPCONT, 8., Rio de Janeiro. São Paulo: ANPCONT.

Formigoni, H. (2008). A influência dos incentivos fiscais sobre a estrutura de capital e a rentabilidade das companhias abertas brasileiras não financeiras (Tese de Doutorado). Universidade de São Paulo, Programa de Pós-Graduação em Controladoria e Contabilidade, São Paulo.

Fortin, H., Hirata Barros, A. C., \& Cutler, K. (2010). Accounting for Growth in Latin America and the Caribbean: Improving Corporate Financial reporting to Support Economical Development. The World Bank.

Franko, P. (2018). The puzzle of Latin American economic development. Rowman \& Littlefield.

Girma, S., Görg, H., \& Strobl, E. (2007). The effect of government grants on plant level productivity. Economics Letters, 94(3), 439-444.

Gujarati, D. N. (2006). Econometria Básica. 4. ed. Rio de Janeiro: Elsevier.

Hair, J. F., Black, W. C., Babin, B. J., Anderson, R. E., \& Tatham, R. L. (2009). Análise Multivariada de Dados. Bookman Editora.

Hall, G. C., Hutchinson, P. J., \& Michaelas, N. (2004). Determinants of the capital structures of European SMEs. Journal of Business Finance \& Accounting, 31(5-6), 711-728.

Jiménez, J. P., \& Podestá, A. (2009). Inversión, incentivos fiscales y gastos tributarios en América Latina. Cepal.

Jorgenson, D. W. (1963). Capital theory and investment behavior. The American Economic Review, 53(2), 247-259.

Kannebley Jr, S., \& Silveira Porto, G. (2012). Incentivos fiscais à pesquisa, desenvolvimento e inovação no Brasil: uma avaliação das políticas recentes. Inter-American Development Bank.

Klemm, A. (2010). Causes, benefits, and risks of business tax incentives. International Tax and Public Finance, 17(3), 315-336.

Klemm, A., \& Van Parys, S. (2012). Empirical evidence on the effects of tax incentives. International Tax and Public Finance, 19(3), 393-423. 
Klette, T. J., Møen, J., \& Griliches, Z. (2000). Do subsidies to commercial R\&D reduce market failures? Microeconometric evaluation studies. Research policy, 29(4-5), 471-495.

Lamonica, M. T., \& Feijó, C. A. (2007). Crescimento e industrialização no Brasil: As lições das leis de Kaldor. In Anais, $35^{\circ}$ Encontro Nacional De Economia, 35., 2007, Recife. Niterói: ANPEC.

Leite, M. G. (2005). Tópicos especiais de finanças públicas economia política das finanças subnacionais: teoria e análise empírica para os estados brasileiros e Distrito Federal na década de noventa. Disponível em: <http://www3.tesouro.fazenda.gov.br/Premio_TN/XPremio/financas/MH2tefpXPTN /mh2_permio_tefp.pdf >

Li, W. (2002). Entrepreneurship and government subsidies: A general equilibrium analysis. Journal of Economic Dynamics and control, 26(11), 1815-1844.

Loureiro, D. Q., Gallon, A. V., \& De Luca, M. M. M. (2011). Subvenções e assistências governamentais (SAG): evidenciação e rentabilidade das maiores empresas brasileiras. Revista de Contabilidade e Organizações, 5(13), 34-54.

Myers, S. C. (1984). The capital structure puzzle. The Journal of Finance, 39(3), 574-592.

Moreira, N. V. A., de Almeida, F. A. S., de Matheus Cota, M. F., \& Sbragia, R. (2007). A inovação tecnológica no Brasil: os avanços no marco regulatório e a gestão dos fundos setoriais. REGE Revista de Gestão, 14, 31-44.

Peters, A., \& Fisher, P. (2004). The failures of economic development incentives. Journal of the American Planning Association, 70(1), 27-37.

Mattos, A. J. M. (2017). Maximização da utilidade esperada, planejamento tributário e governança corporativa (Dissertação de Mestrado). Universidade de São Paulo - Ribeirão Preto, Programa de PósGraduação em Controladoria e Contabilidade, Ribeirão Preto.

Rezende, A. J. (2015). Avaliação do impacto dos incentivos fiscais sobre os retornos e as políticas de investimento e financiamento das empresas (Tese de Livre Docência). Universidade de São Paulo, Faculdade de Economia, Administração e Contabilidade, Ribeirão Preto.

Rodrigues Júnior, M. S. R. A. (2003). DVA como instrumento para mensuração da relação custo-benefício na concessão de incentivos fiscais: um estudo de casos (Tese de Doutorado). Universidade de São Paulo, Programa de Pós-Graduação em Controladoria e Contabilidade, São Paulo.

Santos, A., \& Alencar, R. (2010). Contabilidade societária: uma nova abordagem: aula 06. São Paulo: FIPECAFI, 2010. Disponível em: <http://aulavirtual.fipecafi.com.br/cna/CNA_Aula06/ CNA_Aula06.pdf>

Sekaran, U., \& Bougie, R. (2009). Research methods for business: A skill building approach. John Wiley \& Sons.

Selau, L. P. R., \& Ribeiro, J. L. D. (2009). Uma sistemática para construção e escolha de modelos de previsão de risco de crédito. Gestão e Produção, 16(3), 398-413.

Sullivan, D. M. (2002). Local governments as risk takers and risk reducers: An examination of business subsidies and subsidy controls. Economic Development Quarterly, 16(2), 115-126.

Taveira, J. H. P. S. (2009). Conformidade do disclosure das subvenções governamentais nas empresas de capital aberto (Dissertação de Mestrado). Faculdades IBMEC, Programa de Pós-Graduação em Administração, Rio de Janeiro.

Tokila, A., Haapanen, M., \& Ritsilä, J. (2008). Evaluation of investment subsidies: when is deadweight zero? International Review of Applied Economics, 22(5), 585-600.

World Trade Organization (WTO). (1994). Agreement on subsidies and countervailing measures. 229-272. Disponível em: 〈https://www.wto.org/english/docs_e/legal_e/legal_e.htm>.

Zee, H. H., Stotsky, J. G., \& Ley, E. (2002). Tax incentives for business investment: a primer for policy makers in developing countries. World development, 30(9), 1497-1516.

Zilli, J. C., Figueredo, F. B., Vieira, A. C. P., Watanabe, M., \& Souza, I. R. (2014). Incentivos fiscais, financeiros e regimes aduaneiros vinculados a atividade exportadora no Brasil. In Anais, $14^{\mathrm{a}}$ Mostra de Iniciação Científica, Pós-Graduação, Pesquisa e Extensão. Disponível em: <http://www.ucs.br/etc /conferencias/index.php/mostraucsppga/mostrappga2014/paper/view/3738 >

Zucchi, A. L. (2013). Utilização da informação contábil na adesão aos incentivos fiscais de inovação tecnológica estabelecidos pela Lei 11.196/05 (Tese de Doutorado). Universidade de São Paulo, Programa de Pós-Graduação em Controladoria e Contabilidade, São Paulo. 